\title{
AMOR DE CAPITU?
}

\author{
Clarice Lotermann*
}

"T 7 iver não é necessário. Necessário é criar”, diz Fernando Pessoa. ${ }^{1}$ No contexto da pós-modernidade, pode-se dizer que criar não é necessário. Necessário é parodiar. A produção literária contemporânea revela-se, cada vez mais, sintonizada com a prática da paródia e do pastiche. A originalidade - valor caro aos românticos - hoje já não é o valor primeiro de uma obra de arte e o diálogo que romances contemporâneos estabelecem com obras canônicas é sinal de vitalidade. A tradição é tratada de modo irreverente e dessacralizado e, embora se reconheça o valor do cânone, ele não é visto como algo intocável em sua aura artística. Pelo contrário, é possível brincar com ele, rir dele de forma lúdica e até mesmo zombeteira.

Nesse sentido, o objetivo do presente trabalho é mostrar como a ficção brasileira contemporânea vem assimilando essa tendência da produção literária pós-moderna e, mais especificamente, o diálogo estabelecido por obras que se voltam para a metaficção historiográfica, conceito formulado por Linda Hutcheon na obra Poética do Pós-modernismo. ${ }^{2}$ Para tanto, será focalizada, particularmente, uma obra ficcional contemporânea em que o autor se volta para uma obra canônica

* Universidade Federal do Paraná.

1 Apud FONSECA, Cristina (Org.). O pensamento vivo de Fernando Pessoa. São Paulo: Martin Claret, 1986. p. 6.

2 HUTCHEON, Linda. Poética do pós-modernismo: história, teoria, ficção. Rio de Janeiro: Imago, 1991. 
da literatura brasileira, qual seja, Amor de Capitu $(A C)^{3}$ - de Fernando Sabino que estabelece uma relação direta com a obra machadiana Dom Casmurro $(D C){ }^{4}$

Nas propostas culturais pós-modernas, o romance não é mais considerado como representação do mundo (como se o narrado correspondesse à realidade ou à verdade). É criação de mundo: mundo de palavras que se reconhece feito de palavras e em diálogo com outros mundos de palavras, dentre os quais o universo ficcional. Segundo Steven Connor,

...os relatos mais aceitos da ficção pós-moderna acentuam a prevalência da "metaficção" paródica, ou a exploração pelos textos literários de sua própria natureza de condição de ficção. ${ }^{5}$

Analisando as principais contribuições de Fredric Jameson ao debate sobre o pós-modernismo, Connor salienta que, no estágio pós-moderno,

os signos são libertos por inteiro de sua função de referir-se ao mundo, o que produz a expansão do poder do capital no domínio do signo, da cultura e da representação, ao lado do colapso do valorizado espaço da autonomia típico do modernismo. ${ }^{6}$

Assim, de acordo com Jameson, ficamos

com aquele jogo puro e aleatório de significantes que denominamos pós-modernismo e que já não produz obras monumentais do

3 SABINO, Fernando. Amor de Capitu. 4. ed. São Paulo: Ática, 2001.

4 MACHADO DE ASSIS, Joaquim Maria. Dom Casmurro. 16. ed. São Paulo: Ática, 1985.

5 CONNOR, Steven. Cultura pós-moderna: uma introdução às teorias do contemporâneo. 4. ed. São Paulo: Loyola, 2000. p. 103-104.

6 Ibid., p. 45. 
tipo modernista, mas rearranja sem cessar os fragmentos de textos preexistentes, os blocos de construção da produção social e cultural mais antiga, em alguma nova e exaltada bricolagem: metalivros que canibalizam outros livros, metatextos que unem pedaços de outros textos. ${ }^{7}$

Essa marca pós-moderna é analisada por Linda Hutcheon na já citada obra Poética do pós-modernismo, na qual a autora discute acerca da metaficção, mais propriamente da metaficção historiográfica, apontando-a como característica fundamental da ficção pós-moderna. Discorrendo sobre as três maneiras elencadas por Umberto Eco para narrar o passado (a fábula, a estória heróica e o romance histórico), Hutcheon acrescenta uma quarta: "a metaficção historiográfica - e não a ficção histórica - , com sua intensa autoconsciência em relação à maneira como tudo é realizado". 8

Nesse contexto, destaca-se o uso da paródia como recurso metaficcional por excelência. No diálogo que novos textos estabelecem com textos, via de regra, canônicos, a paródia é quase onipresente, uma vez que a retomada se dá pelo viés da ironia.

Estudando mais detidamente a paródia, Linda Hutcheon pontua :

A maioria dos teóricos da paródia remontam a raiz etimológica do termo ao substantivo grego parodia, que quer dizer "contracanto", e ficam-se por aí. Se olharmos mais atentamente para essa raiz obteremos, no entanto, mais informação. A natureza textual ou discursiva da paródia (por oposição à sátira) é evidente no elemento odos da palavra, que significa canto. O prefixo para tem dois significados, sendo geralmente mencionado apenas um deles - o de "contra" ou de "oposição". (...) No entanto, para em grego também pode significar "ao longo de" e, portanto, existe uma sugestão de acordo ou intimidade, em vez de contraste. (...) A paródia é, pois, na sua irônica "transcontextualização" e inversão, repetição com diferença. ${ }^{9}$

7 Apud CONNOR, op. cit., p. 45.

8 HUTCHEON, 1991, op. cit., p. 150.

9 HUTCHEON, Linda. Uma teoria da paródia. Ensinamento das formas de arte do século XX. Lisboa: Edições 70, 1989. p. 47-48. 
Ao apontar para o duplo significado de paródia, a autora também estabelece diferença entre esta e a imitação, a citação e a alusão - "Ao contrário da imitação, da citação ou até da alusão, a paródia exige essa distância irônica e crítica" - e o pastiche que "opera mais por semelhança e correspondência (...) a paródia é transformadora no seu relacionamento com outros textos; o pastiche é imitativo". ${ }^{10}$ E enfatiza: "A paródia está para o pastiche talvez como a figura de retórica está para o clichê. No pastiche e no clichê, pode dizer-se que a diferença se reduz à semelhança". ${ }^{11}$

É a partir desses pressupostos que se pretende, neste trabalho, analisar a obra Amor de Capitu, de Fernando Sabino. A começar pelo título, destaca-se o fato de uma personagem ficcional de um texto canônico migrar para ali. $\mathrm{O}$ diálogo com a obra de Machado de Assis é mais do que evidente. Na capa consta, após o nome do autor: "Leitura fiel do romance de Machado de Assis sem o narrador Dom Casmurro". E ainda: "Recriação literária".

No interior do livro, novas indicações remetem à obra machadiana: uma epígrafe retirada de Dom Casmurro e uma Apresentação em que o autor justifica sua empreitada: "A recriação aqui apresentada se inspirou no reconhecimento da importância de um dos monumentos da nossa literatura" $(A C$, p. 7). Além disso, num capítulo intitulado "E bem, e o resto?" (título do último capítulo do romance de Machado de Assis, tomado em homenagem a ele), Fernando Sabino discorre sobre os procedimentos adotados na feitura de seu livro, dentre os quais a narrativa em terceira pessoa, "sem a interveniência de interpretações pessoais posteriores, muitas vezes deformadas pelo tempo decorrido" ( $A C, \mathrm{p}$. 232) e a exclusão de algumas partes do romance a que se reporta:

A eliminação do intermediário levou-me à fusão de um ou outro capítulo, ou à sua transferência no contexto, sem prejuízo do entrecho e preservando na estrutura romanesca o espírito machadiano da concepção original. ( $A C$, p. 232)

Como Apêndice, constam alguns trechos de Dom Casmurro, apresentados como "exemplos de excelentes crônicas de época" e comentários de Dom Casmurro sobre si mesmo e sobre fatos do seu tempo ( $A C$, p. 235).

10 HUTCHEON, 1989, op. cit., p. 50.

11 Ibid., p. 55. 
Sobre esse procedimento - a migração de personagens canônicas da literatura para obras contemporâneas - e particularmente no caso de Capitu uma das personagens mais conhecidas no âmbito da literatura brasileira -, Marilene Weinhardt destaca:

Na produção crítica, não faltam estudiosos que apontem a força da figuração de Capitu, esbanjando-se adjetivos para qualificá-la. Quando se transita da influência para o que vem sendo chamado de crítica-ficção, ainda que sem levantamento exaustivo, parece ser possível afirmar, sem muito risco de erro, que é o caso mais significativo, numericamente, na ficção brasileira, seja tendo em vista o título Dom Casmurro, seja tendo em vista uma personagem em particular. ${ }^{12}$

Amor de Capitu constrói-se como uma repetição ipsis litteris do romance de Machado de Assis, exceptuando-se as partes que foram omitidas porque são comentários do narrador machadiano sobre si mesmo ou sobre fatos do seu tempo. Considerando-se que, na obra de Fernando Sabino, o foco narrativo foi alterado para a terceira pessoa, os capítulos iniciais de Dom Casmurro são suprimidos porque não há, em princípio, um Dom Casmurro explicando o porquê do título e do livro. Na obra machadiana, o narrador Dr. Bento Santiago se põe a escrever um livro com o "fim evidente [de] atar as duas pontas da vida, e restaurar na velhice a adolescência" ( $D C, \mathrm{p} .12)$. Com a mudança na focalização, a obra de Sabino omite tais dados e começa com a cena em que, escondido atrás da porta, Bentinho ouve uma conversa entre sua mãe e o agregado José Dias:

Quando Bento Santiago ia entrando na sala de visitas, ao ouvir José Dias falar seu nome, escondeu-se atrás da porta. A casa era a da Rua de Matacavalos, o mês de novembro, o ano de 1857. $(A C$, p. 11)

12 WEINHARDT, Marilene. Dom Casmurro na ficção contemporânea. In: ENCONTRO DA ASSOCIAÇÃO BRASILEIRA DE LITERATURA COMPARADA ABRALIC, 8., 2002, Belo Horizonte. Anais... Belo Horizonte: UFMG, 2002. p. 1. 
A omissão dos primeiros capítulos, em que o narrador machadiano explicava as razões do seu apelido - e título da obra -, assim como os motivos que o levaram a escrever, induzem o narrador de Sabino a uma situação bastante artificial quando, ao finalizar sua narrativa, apenas comenta: "E não tendo nada de melhor a fazer, começou a pensar em escrever um livro" ( $A C$, p. 227).

Grosso modo, a obra de Fernando Sabino centra a narrativa na história de Capitu e Bentinho, partindo do princípio da "óbvia infidelidade da personagem principal" ( $A C$, p. 8). Na explicação ao final do livro - Apêndice -, o escritor deixa evidenciada a sua intenção de escrever uma obra em que procura

reviver os acontecimentos do livro a partir do mesmo ângulo do narrador original, com os mesmos elementos prosódicos, sem a interveniência de interpretações pessoais posteriores... ( $A C, \mathrm{p}$. 232)

Assim, Fernando Sabino cria, na verdade, uma onisciência seletiva, pois a perspectiva narrativa continua sendo a de Bento Santiago. Lígia C. M. Leite, comentando a tipologia de Norman Friedman, diz que a onisciência seletiva,

como no caso do narrador-protagonista, [caracteriza-se pela] limitação a um centro fixo. $O$ ângulo é central, e os canais são limitados aos sentimentos, pensamentos e percepções da personagem central, sendo mostrados diretamente. ${ }^{13}$

Ao iniciar a leitura, instigado pela indicação da capa, é inevitável que o leitor se pergunte: como será essa Capitu sem ser mostrada pelos olhos do Dom Casmurro? No entanto, a mera transposição de um narrador-protagonista para um narrador cuja onisciência é seletiva não altera em nada a visão que se tem de

13 LEITE, Lígia Chiappini Moraes. O foco narrativo. 4. ed. São Paulo: Ática, 1989. p. 54 
Capitu, pois a personagem continua sem voz, continua tendo a sua história contada sob a perspectiva do marido, o casmurro Dr. Bento Santiago. "É essa a perspectiva que impera sempre, não se cria outro observador, onisciente ou não". ${ }^{14}$

Isto pode ser observado, a título de exemplificação, na clássica cena do velório de Escobar, em que Bento Santiago credita o choro de Capitu à traição dela com o amigo. Tanto em Machado de Assis quanto em Fernando Sabino não há espaço para a versão de Capitu. Os narradores (ou, melhor, o narrador Bento Santiago, que continua sendo o dono da voz na obra de Sabino) descrevem a cena sempre do ponto de vista de Bento, sem outra perspectiva que relativizasse aquela ou colocasse em evidência os pensamentos/sentimentos de Capitu. Em Dom Casmurro, Bento diz que

A confusão era geral. No meio dela, Capitu olhou alguns instantes para o cadáver tão fixa, tão apaixonadamente fixa, que não admira lhe saltassem algumas lágrimas poucas e caladas.(...) Momento houve em que os olhos de Capitu fitaram o defunto, quais os da viúva, sem o pranto nem palavras desta, mas grandes e abertos, como a vaga do mar lá fora, como se quisesse tragar também o nadador da manhã. ( $D C$, p. 134)

Na obra de Sabino diz-se que

...Bento viu Capitu a olhar alguns instantes para o cadáver de maneira tão fixa, tão apaixonadamente fixa, que não se admirou ao lhe saltarem dos olhos algumas poucas e silenciosas lágrimas. (...) Houve um momento em que Bento viu os olhos de Capitu fitarem o defunto, como os de viúva, sem o pranto nem as palavras dela, mas grandes e abertos, como a vaga do mar lá fora como se quisesse tragar também o nadador daquela manhã. ( $A C$, p. 194)

14 WEINHARDT, op. cit., p. 4. 
Não se acrescenta nada, não se altera nada: tudo continua sendo contado por Bento Santiago. Logo, o exercício de transposição para um narrador em terceira pessoa revela-se inútil e absolutamente dispensável.

Da mesma forma, são as lembranças de Bento Santiago que interessam ao narrador de Sabino e lhe fornecem informações sobre fatos ocorridos no passado:

Bento se lembrava das palavras do finado Gurgel, quando the mostrou em sua casa o retrato da mulher, parecido com Capitu (...). Lembrava-se de episódios vagos e remotos, palavras, encontros e incidentes, tudo em que a sua cegueira não pusera malícia, e a que faltou o velho ciúme. (...) todas essas reminiscências lhe vinham agora, em tal atropelo que se sentiu atordoado... ( $A C$, p. 215)

Quanto à Capitu, já fora silenciada na Europa...

Ao comentar seu exercício de recriação literária, Fernando Sabino diz que a eliminação do intermediário levou-o à fusão de um ou outro capítulo, sem prejuízo do entrecho e preservando na estrutura romanesca o espírito machadiano. Contudo, ao suprimir e resumir certas partes, o espírito machadiano - marcado pela ironia, por constantes digressões, interrupções, alusões, referências ao leitor, ou seja, por um vasto material que excede o enredo propriamente dito desaparece da obra. Onde terá ido parar a peculiar ironia machadiana? $\mathrm{Na}$ transposição de Sabino, tudo se perdeu, como pode ser observado na contraposição de dois trechos:

Dom Casmurro: "O destino não é só dramaturgo, é também, o seu próprio contra-regra, isto é, designa a entrada dos personagens em cenas, dá-lhes cartas e outros objetos (...) assim se explicam a minha estada debaixo da janela de Capitu e a passagem de um cavaleiro, um $d a n d y$, como então dizíamos. (...) Ora o dandy do cavalo baio não passou como os outros; era a trombeta do juízo final e soou a tempo; assim faz o Destino, que é o seu próprio 
contra-regra. O cavaleiro não se contentou de ir andando, mas voltou a cabeça para o nosso lado..." (DC, p. 89)

Amor de Capitu: "Naquele momento passava por ali um cavaleiro, um dândi, como então se dizia. Montava um belo cavalo alazão, firme na sela (...). Só que o dândi do cavalo alazão não passou como os demais: o cavaleiro não se contentou em ir andando, mas voltou a cabeça para o lado deles,...” $(A C$, p. 118)

Dom Casmurro: "Sucedeu que a minha ausência foi logo temperada pela assiduidade de Capitu. (...) a esperança de que o nosso amor, tornando-me absolutamente incompatível com o seminário, me levasse a não ficar lá nem por Deus nem pelo diabo, esta esperança íntima e secreta entrou a invadir o coração de minha mãe. Ela ficava comigo sem ato propriamente seu. Era como se, tendo confiado a alguém a importância de uma dívida para levá-la ao credor, o portador guardasse o dinheiro consigo e não levasse nada. Na vida comum, o ato de terceiro não desobriga o contratante; mas a vantagem de contratar com o céu é que intenção vale dinheiro. Hás de ter tido conflitos parecidos com esse, e, se és religioso, haverás buscado alguma vez conciliar o céu e a terra, por modo idêntico ou análogo." $(D C$, p. 95)

Amor de Capitu: "Aconteceu que sua ausência foi logo temperada pela assiduidade de Capitu. Esta começou a se tornar necessária. E pouco a pouco a mãe se persuadiu de que a menina faria seu filho feliz. Então, veio a esperança de que o amor deles, tornandoo absolutamente incompatível com o seminário, o levasse a não fícar lá nem por Deus nem pelo diabo. Para ele, esta esperança íntima e secreta começou a invadir o coração de sua mãe. Neste caso, o filho romperia o contrato sem que ela tivesse culpa. $\mathrm{Na}$ verdade, ela agora não podia mais ter Capitu longe de si..." $(A C$, p. 130)

Tanto no primeiro quanto no segundo trecho em evidência, a omissão das reflexões sobre o Destino e sobre o caráter mercantilista da religião empobrecem sobremaneira a narrativa dos eventos focalizados. Disto se depreende que, embora a intenção fosse homenagear Machado de Assis, a narrativa de Fernando Sabino peca por omitir o que há de mais machadiano. $\mathrm{O}$ que reforça a idéia de que nem só de enredo vive o romance... 
Em face desse exercício de recriação ficcional, e tendo como pressuposto as afirmações de Linda Hutcheon sobre a paródia, como pode ser classificado o livro de Fernando Sabino?

Convém ressaltar que, mesmo na modalidade respeitosa, a paródia requer distanciamento crítico; mesmo sendo homenagem, pressupõe repetição com diferença:

É (...) importante não esquecer que esta variedade reverente de paródia é como o tipo mais pejorativo num aspecto significativo: também aponta para a diferença entre textos. Muito embora a paródia marcada pelo respeito se ache mais próxima da homenagem do que do ataque, essa distanciação crítica e marcação de diferença continua a existir. ${ }^{15}$

Ora, no texto de Fernando Sabino não se observa essa diferença entre textos. Muito embora ele tenha suprimido algumas partes de Dom Casmurro, Amor de Capitu não pode ser considerado como paródia do texto machadiano e sim como pastiche, pois opera por semelhança e imitação e não por distância irônica e crítica.

Do que se conclui que, sem seguir a máxima pessoana e tampouco a sua paródia, Fernando Sabino construiu uma obra que estaria melhor intitulada por: "Amor de Bentinho: leitura infiel de Machado de Assis". 


\section{RESUMO}

Este estudo, que acrescenta uma interrogação ao título do romance Amor de Capitu, de Fernando Sabino, traz à baila a discussão sobre cânone e paródia, para concluir que o romance se limita ao pastiche, sem alcançar o distanciamento crítico produzido pela ironia.

Palavras-chave: ficção histórica, metaficção, Fernando Sabino.

\section{ABSTRACT}

This study, which adds a question mark to the title of the novel Amor de Capitu, by Fernando Sabino, brings up the discussion about canon and parody, and the conclusion is that the novel is just a pastiche and it doesn't achieve the critical distancing created by irony.

Key-words: historical fiction, metafiction, Fernando Sabino.

\section{REFERÊNCIAS}

CONNOR, Steven. Cultura pós-moderna: introdução às teorias do contemporâneo. 4. ed. São Paulo: Loyola, 2000.

HUTCHEON, Linda. Uma teoria da paródia. Ensinamento das formas de arte do século XX. Lisboa: Edições 70, 1989.

.Poética do pós-modernismo: história, teoria, ficção. Rio de Janeiro: Imago, 1991.

. Teoria e política da ironia. Belo Horizonte: Ed. da UFMG, 2000.

LEITE, Lígia Chiappini Moraes. O foco narrativo. 4. ed. São Paulo: Ática, 1989.

LEENHARDT, Jacques; PESAVENTO, Sandra Jatahy (Orgs.). Discurso histórico e narrativa literária. Campinas: Ed. da Unicamp, 1998.

MACHADO DE ASSIS, Joaquim Maria. Dom Casmurro. 16. ed. São Paulo: Ática, 1985.

SABINO, Fernando. Amor de Capitu. 4. ed. São Paulo: Ática, 2001. 
SCHWARZ, Roberto. A poesia envenenada de Dom Casmurro. In: SCHWARZ, Roberto. Duas meninas. São Paulo: Cia. das Letras, 1997.

WEINHARDT, Marilene. As vozes documentais no discurso romanesco. In: FARACO, Carlos Alberto; TEZZA, Cristóvão; CASTRO, Gilberto de (Orgs.). Diálogos com Bakhtin. 3. ed. Curitiba: Ed. UFPR, 2001. p. 337-360.

. Quando a história literária vira ficção. In: ANTELO, Raul et al. (Orgs.). Declínio da arte ascensão da cultura. Florianópolis: Letras Contemporâneas e Abralic, 1998.

. Dom Casmurro na ficção contemporânea. In: ENCONTRO DA ASSOCIAÇÃO BRASILEIRA DE LITERATURA COMPARADA - ABRALIC, 8., 2002, Belo Horizonte. Anais... Belo Horizonte: UFMG, 2002. 